\title{
CUDC-907 reverses pathological phenotype of keloid fibroblasts in vitro and in vivo via dual inhibition of PI3K/Akt/mTOR signaling and HDAC2
}

\author{
TIAN TU $^{1,2^{*}}$, JIA HUANG $^{1,2^{*}}$, MIAOMIAO LIN $^{3 *}$, ZHEN GAO $^{1}$, XIAOLI WU ${ }^{1}$, \\ WENJIE ZHANG ${ }^{1,2}$, GUANGDONG ZHOU ${ }^{1,2}$, WENBO WANG ${ }^{1,2}$ and WEI LIU ${ }^{1,2}$ \\ ${ }^{1}$ Department of Plastic and Reconstructive Surgery and ${ }^{2}$ Shanghai Key Laboratory of Tissue Engineering Research, \\ Shanghai Ninth People's Hospital, Shanghai Jiao Tong University School of Medicine, Shanghai 200011; \\ ${ }^{3}$ Department of Otolaryngology, Suzhou First People's Hospital, Suzhou, Anhui 234000, P.R. China
}

Received April 18, 2019; Accepted September 2, 2019

DOI: $10.3892 /$ ijmm.2019.4348

\begin{abstract}
Keloids are benign skin tumors with a high recurrence rate following surgical excision. Abnormal intracellular signaling is one of the key mechanisms involved in its pathogenesis. Over-activated phosphoinositide 3-kinase/RAC-alpha serine/threonine-protein kinase/mammalian target of rapamycin (PI3K/Akt/mTOR) signaling pathway and overproduction of histone deacetylases 2 (HDAC2) have also been observed in keloid fibroblasts (KFs). The present study aimed to explore the possibility of reversing the KF pathological phenotype using CUDC-907, a dual inhibitor of PI3K/Akt/mTOR pathway and HDACs. KFs and keloid xenografts were treated with CUDC-907 to examine its inhibitory effects on the pathological activities of KFs in vitro and in vivo. CUDC-907 inhibited cell proliferation, migration, invasion and extracellular matrix deposition of in vitro cultured KFs and also suppressed collagen accumulation and disrupted the capillaries of keloid explants ex vivo and in vivo. A mechanistic study of CUDC-907 revealed the initiation of cell cycle arrest at G2/M phase along with the enhanced expression of cyclin-dependent
\end{abstract}

Correspondence to: Professor Wei Liu or Dr Wenbo Wang, Department of Plastic and Reconstructive Surgery, Shanghai Ninth People's Hospital, Shanghai Jiao Tong University School of Medicine, 639 Zhi Zao Ju Road, Shanghai 200011, P.R. China

E-mail: liuwei_2000@yahoo.com

E-mail: wangwenbo0903@126.com

*Contributed equally

Abbreviations: PI3K, phosphoinositide 3-kinase; Akt, RAC-alpha serine/threonine-protein kinase; mTOR, mammalian target of rapamycin; HDAC2, histone deacetylases 2; KFs, keloid fibroblasts; ECM, extracellular matrix; HUVECs, human umbilical vein endothelial cells

Key words: CUDC-907, KF, HDAC, PI3K/AKT/mTOR signaling, dual inhibitor kinase inhibitor 1 and decreased expression of cyclin B in cells treated with CUDC-907. CUDC-907 not only inhibited AKT and mTOR phosphorylation and promoted the acetylation of histone $\mathrm{H} 3$, but also significantly inhibited the phosphorylation levels of Smad2/3 and Erk. These preclinical data demonstrating its anti-keloid effects suggest that CUDC-907 may represent a candidate drug for systemic keloid therapy.

\section{Introduction}

Keloid formation results from an abnormal wound healing process that is characterized by excessive extracellular matrix (ECM) deposition and dermal fibroblast hyperproliferation (1). Even though several therapeutic options are available at present, the frustrating clinical prognosis and the high recurrence rates require solutions, to improve clinical outcomes $(2,3)$. Keloids are considered to be benign skin tumors due to the similar characteristics between keloid fibroblasts (KFs) and tumor cells (4). Keloids have exhibited a series of tumor-like pathological features, such as increasing ATP synthesis, inflammation-induced alteration of the stem cell niche and histological heteromorphism, in which normal dermal tissue structures disappear (5-7). Due to the similarities between keloids and benign skin tumors, a large number of anti-keloid compounds have been investigated for their therapeutic values from the perspective of anti-tumor like effects on keloid formation $(1,8-12)$.

The key pathogenetic events that occur in dermal fibroblasts during post-trauma keloid formation remain unclear. Activation of phosphoinositide 3-kinase/RAC-alpha serine/threonine-protein kinase/mammalian target of rapamycin (PI3K/Akt/mTOR) pathway was demonstrated to enhance inflammation, angiogenesis, and deposition of ECM components in keloids (13) and was therefore suggested to be associated with several fibrous disorders (14). Syed et al (8) described overactivation of mTOR in keloids compared with corresponding extra-lesional regions. Inhibitors targeting mTOR have exhibited their potentials in anti-keloid therapy (11). Histone deacetylases 2 (HDAC2), a second verified factor that may participate in the progression of 
fibrotic development, but no other type of HDAC, has been confirmed to be overexpressed in keloid and hypertrophic scars (15). As HDAC inhibitors have been widely exploited for their anti-fibrosis effects on liver/kidney fibrosis (16) and their anti-cancer roles (17), they may also represent promising therapeutic drugs for keloid disease (9).

Therefore, CUDC-907, a newly-synthesized small molecular compound that synergistically inhibited both PI3K/Akt/mTOR pathway and HDACs (18) was selected for examination in the present study for its potential therapeutic effect on KFs, as it was previously demonstrated that CUDC-907 exerted a potent anti-tumor effect in B cell lymphoma cell lines (19) and other tumor types (18). Recently, a phase-I clinical trial (trial no. NCT01742988) examining the biosafety, tolerability, and preliminary activity of CUDC-907 demonstrated its potential in future clinical applications (20).

Compared with normal dermal fibroblasts, KFs exhibit abnormal cellular behaviors including enhanced cell proliferation, overproduction and deposition of extracellular matrices like collagens and growth factors such as transforming growth factor- $\beta$ (TGF- $\beta$ ) (21). The present study investigated the anti-keloid effect of CUDC-907 using in vitro cell cultures, ex vivo explant cultures and an in vivo xenograft model, and explored if CUDC-907 was able to reverse the pathological features of in vitro cultured KFs and counteract keloid formation ex vivo and in vivo.

\section{Materials and methods}

Tissue samples acquisition. A total of 47 patients without any previous anti-keloid therapy donated their keloid samples following surgical excision. Patients were informed that their donated tissues would be utilized only for scientific research and written informed consent was provided. These patients included 21 males and 26 females, with ages ranging from 7-72 years old. Patient recruitment was executed from September 2016 to August 2018 in Shanghai Ninth People's Hospital, Shanghai Jiao Tong University School of Medicine. Foreskin samples, which were considered as normal skin samples, were donated by other 4 male patients during this recruitment. All patient information is provided in Table SI. Equal amounts of primary KFs isolated from 3 different patients were mixed as a pooled cell sample to decrease individual variation among different patients. Protocols for the handling of human tissues and cells were approved by the Ethics Committee of Shanghai Ninth People's Hospital.

Chemical reagent preparation. CUDC-907, GDC-0941 and Trichostatin A solid powder were purchased from Selleck Chemicals and dissolved in dimethyl sulfoxide (DMSO). They were diluted in Dulbecco's modified eagle medium (DMEM; Hyclone; GE Healthcare Life Sciences) to produce the designated drug concentrations with DMSO volumes identical to that of vehicle control group. The final concentration of DMSO solvent was controlled under $0.00032 \%$ (v/v) during each of the subsequent assays.

Isolation and culture of keloid and normal dermal fibroblasts. Isolation and culture of fibroblasts were performed according to a previously described protocol (12). Keloids or foreskin were treated with $0.3 \%$ (for keloid) or $0.2 \%$ (for foreskin) collagenase (SERVA Electrophoresis GmbH) dissolved in DMEM containing 10\% fetal bovine serum (FBS; Hyclone; GE Healthcare Life Sciences) for $6 \mathrm{~h}$ at $37^{\circ} \mathrm{C}$ on a shaker. Following digestion, cells were collected and resuspended in DMEM supplemented with 10\% FBS and 100X Antibiotic-Antimycotic solution (Gibco; Thermo Fisher Scientific, Inc.). The cells from the secondary culture were used in the following protocols.

Cell proliferation analysis. The KFs from the secondary culture were seeded onto 96-well plates at a density of 1,000 cells/well. Starved cells were treated with medium containing the CUDC-907, GDC-0941 and trichostatin A. Cell proliferation was examined using Cell Counting Kit-8 (CCK-8; Dojindo Molecular Technologies, Inc.) according to the manufacturer's protocol.

Cell cycle analysis. According to a previously described protocol (12), KFs treated with CUDC-907 for 5 days were collected. To examine cell cycle profiles, the washed cells were subsequently fixed in ice-cold $70 \%$ ethanol for $24 \mathrm{~h}$. After centrifugation at $37^{\circ} \mathrm{C}$ and $500 \mathrm{x}$ g for $5 \mathrm{~min}$, cell pellets were then stained using a cell cycle/apoptosis examination kit (Shanghai Qihai Futai Biotechnology Co., Ltd.). A flow cytometer (Beckman Coulter, Inc.) equipped with ModiFit LT v2.0 software was applied to conduct the flow cytometric analyses.

$R N A$ extraction and reverse transcription quantitative polymerase chain reaction $(R T-q P C R)$. Total RNA was extracted using TRIzol ${ }^{\circledR}$ reagent (Thermo Fisher Scientific, Inc.) and quantitated using a DU800 spectrophotometer (Beckman Coulter, Inc.). cDNA was synthesized using AMV reverse transcriptase (Promega Corporation) with $1.5 \mu \mathrm{g}$ total RNA according to the manufacturer's protocol. qPCR was conducted with Power SYBR Green PCR (2X) master mix (Applied Biosystems; Thermo Fisher Scientific, Inc.) in a real-time thermal cycler (Stratagene; Agilent Technologies, Inc.) according to a previously described protocol (22). Thermocycling conditions used in present study were as follows: $95^{\circ} \mathrm{C}$ for $10 \mathrm{~min}$, followed by 40 cycles of $95^{\circ} \mathrm{C}$ for $30 \mathrm{sec}, 58^{\circ} \mathrm{C}$ annealing temperature for $30 \mathrm{sec}$ and $72^{\circ} \mathrm{C}$ for $45 \mathrm{sec}$. GAPDH was employed as an internal control. The primers for this assay are listed in Table SII.

In vitro cell migration and invasion assays. The scratch assay was performed according to a previously described protocol (12). The cell monolayer was scratched using a $200 \mu \mathrm{l}$ pipette tip and then cultured in a serum-free medium without or with CUDC-907 for $48 \mathrm{~h}$. Images were captured at 0,24 and $48 \mathrm{~h}$ after scratching, and migration distances were measured using Image-Pro Plus v6.0 software (Media Cybernetics, Inc.).

Subsequently, a Transwell system (Corning, Inc.) was utilized according to a previously described protocol (12). Starved KFs were seeded in the upper chambers at densities of $3 \times 10^{4}$ or $6 \times 10^{4} /$ well for migration or invasion assays, respectively. In the invasion assay, chambers were pre-coated in $80 \mu \mathrm{l}$ Matrigel (BD Biosciences) at $37^{\circ} \mathrm{C}$ for $30 \mathrm{~min}$ prior to cell seeding. Traversing cells were fixed in $4 \%$ paraformaldehyde for $24 \mathrm{~h}$ and then stained with DAPI (Sigma-Aldrich; Merck 
KGaA). The cell numbers in 5 randomly selected fields were counted using Image-Pro Plus v6.0 software.

Further, an Oris ${ }^{\mathrm{TM}}$ cell migration and invasion assay kit (Platypus Technologies, LLC) were employed as the previously described protocol (11). Briefly, $2.5 \times 10^{4}$ starved KFs were seeded in each well. In the invasion assay, $40 \mu l$ rat tail type I collagen (COL1) solution was used to pre-coat the inserts and incubated at $37^{\circ} \mathrm{C}$ for $30 \mathrm{~min}$. At $0 \mathrm{~h}$ (for background control), $24 \mathrm{~h}$ (for migration) or $48 \mathrm{~h}$ (for invasion), cells in the migration zone were stained using Calcein-AM $(2 \mu \mathrm{M}$; AAT Bioquest, Inc.) at $37^{\circ} \mathrm{C}$ for $30 \mathrm{~min}$ and were counted using Image-Pro Plus v6.0 software.

Western blot analysis. Total proteins were extracted from KFs, which had been treated with or without CUDC- 907 for $16 \mathrm{~h}$ for the cell cycle molecules analysis and $72 \mathrm{~h}$ for the other experiments, using radioimmunoprecipitation assay lysis buffer with $1 \%$ PMSF and 1\% phosphatase inhibitor (Beyotime Institute of Biotechnology). Cell lysates were resolved on $10 \%$ SDS-PAGE gels. A mass of $40 \mu \mathrm{g}$ of protein was loaded in each lane for electrophoresis and then transferred to PVDF membranes. After transferring, membranes were blocked using $5 \%$ nonfat milk (Bio-Rad Laboratories, Inc.) at $37^{\circ} \mathrm{C}$ for $1 \mathrm{~h}$. Immunoblotting was performed according to previously published procedures (12). The membranes were incubated with primary antibodies and subsequently incubated with secondary antibodies conjugated with horseradish peroxidase. All details regarding the antibodies used are summarized in Table SIII. An enhanced chemiluminescence detection system was applied to visualize the protein bands. ImageJ (version 1.8.0; National Institutes of Health) was used to perform the densitometric analysis.

Ex vivo explant culture of keloid tissue. The keloid tissue isolated following epidermal removal was minced into $3 \times 2 \times 2 \mathrm{~mm}^{3}$ fragments. A total of 20 small pieces were assigned into each group randomly and seeded onto a culture dish with DMEM (10\% FBS) and CUDC-907. Representative micrographs were captured in the same location for each culture group, and KFs were collected for counting at day 7 after the treatment, as previously described (12).

Hematoxylin and eosin staining. Tissue samples were fixed in $4 \%$ paraformaldehyde at $4^{\circ} \mathrm{C}$ overnight, embedded in paraffin blocks, and then sectioned to a $5 \mu \mathrm{m}$ thickness. After complete removal of paraffin, these sections were stained with a hematoxylin and eosin staining kit (Beyotime Institute of Biotechnology) according to the manufacturer's instructions. Staining procedures were conducted at room temperature. Images were captured via light microscopy at x200 magnification.

Immunohistochemical staining. This experiment was performed according to a previously published protocol (12). The primary and secondary antibodies (Table SIII) were diluted according to the manufacturer's protocol and target antigens were visualized with a DAB horseradish peroxidase color development kit (Beyotime Institute of Biotechnology), according to the manufacturer's instructions, or with the GTVision ${ }^{\mathrm{TM}}$ III detection system/Mo\&Rb (Dako; Agilent Technologies, Inc.). Images were captured through a light microscopy at x100 or x 200 magnification. Fold changes in integral optical density were measured using Image-Pro Plus 6.0 and platelet endothelial cell adhesion molecule-positive $\left(\mathrm{CD} 31^{+}\right)$and hematopoietic progenitor cell antigen-positive $\left(\mathrm{CD} 34^{+}\right)$blood vessel numbers were counted in 5 randomly selected fields.

In vitro tube formation assay. Human umbilical vein endothelial cells (HUVECs), kindly provided by Shanghai Key Laboratory of Tissue Engineering, were seeded in each well of a 96 well plate $\left(1.5 \times 10^{4}\right.$ per well) where $50 \mu 1$ Matrigel had been pre-incubated at $37^{\circ} \mathrm{C}$ for $1 \mathrm{~h}$. After incubation at $37^{\circ} \mathrm{C}$ for $16 \mathrm{~h}$, images of newly formed capillary-like structures were observed via a phase-contrast light microscope at x40 magnification and semi-quantitatively analyzed as previously described (23).

Keloid xenograft model in nude mice. According to a previously published protocol (24), a total of 12 male nude mice (6-week-old; $16.00 \pm 1.48 \mathrm{~g}$ ) purchased from Shanghai Laboratory Animal Centre, Chinese Academy of Sciences were used. The mice were kept in a specific pathogen-free environment where the temperature was maintained at $25^{\circ} \mathrm{C}$ and humidity was 40-70\%, with a light: Dark cycle of 12: $12 \mathrm{~h}$. Animals were kept in their cages with ad libitum access to food and water. Anesthesia was induced via inhalation of $2 \%$ isoflurane $(0.8 \mathrm{l} / \mathrm{min})$ in air for $30 \mathrm{sec}$ and maintained using $1.5 \%$ isoflurane $(0.6 \mathrm{l} / \mathrm{min})$ in air $(25-27)$. Anesthesia was considered successful when the righting reflex was absent or the mice did not respond to toe pinches. All surgeries were conducted under aseptic conditions following the successful induction of anesthesia and all protocols were approved by the Animal Care and Welfare Committee of Shanghai Ninth People's Hospital. Epidermis-intact cylindrical specimens (diameter $=8 \mathrm{~mm}$; height $=3 \mathrm{~mm}$ ) were attached to the backs of the animals, then sutured with 6-0 PDS (Johnson \& Johnson). At 12 days post-surgery, $10 \mu \mathrm{l}$ normal saline solution containing 64 nM CUDC-907 or vehicle were injected into keloid xenografts every 2 days. Animals were sacrificed by cervical dislocation at the 10th day or the 20th day of drug administration and the xenografts were harvested for further histological and immunohistological assessments as aforementioned.

Statistical analysis. All experiments were repeated at least 3 times. All the data are presented as mean \pm standard deviation (SD) or standard error of the mean (SEM). A one-way analysis of variance was used to detect significant difference among multiple groups, followed by a Least Significant Difference post-hoc test using SPSS v22.0 software (IBM Corp). $\mathrm{P}<0.05$ was considered to indicate a statistically significant difference.

\section{Results}

Keloids expresses increased levels of HDAC2, total and $p$-Akt and mTOR. Immunohistochemical staining demonstrated that both total and p-Akt and mTOR were visually identified to be expressed at increased levels in keloid tissue compared with in the extra-lesion areas (Fig. 1A and C). In addition, HDAC2 was also identified visually to be expressed in keloid tissues at an increased level compared with that of the extra-lesion area (Fig. 1E). 

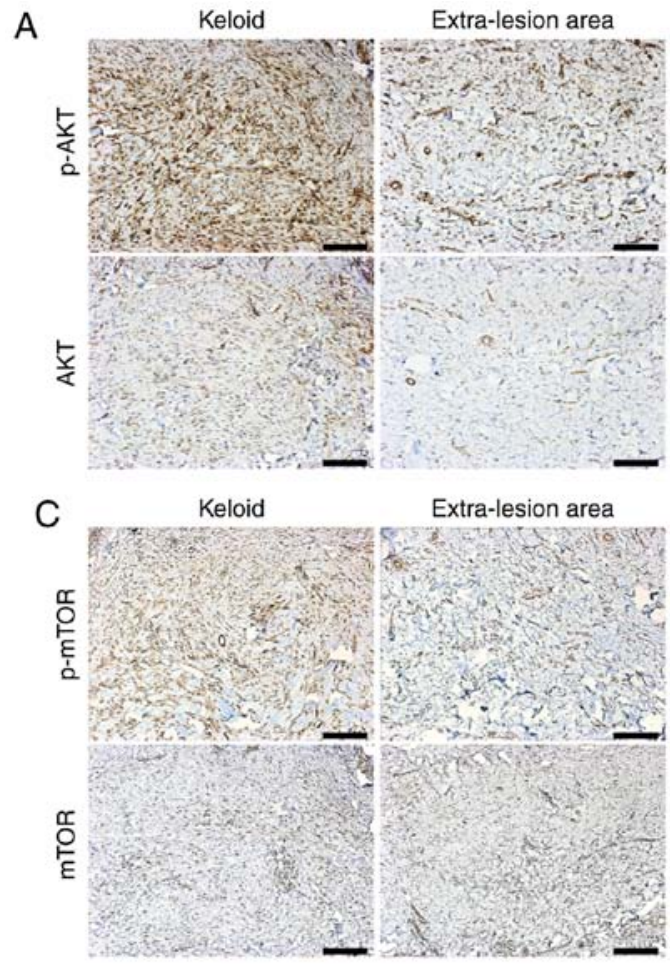

Extra-lesion area

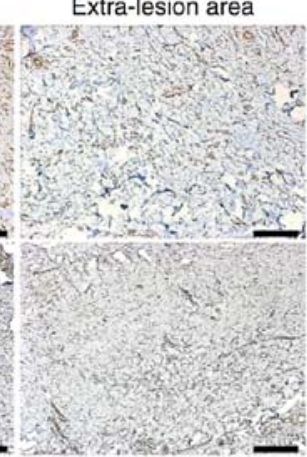

E

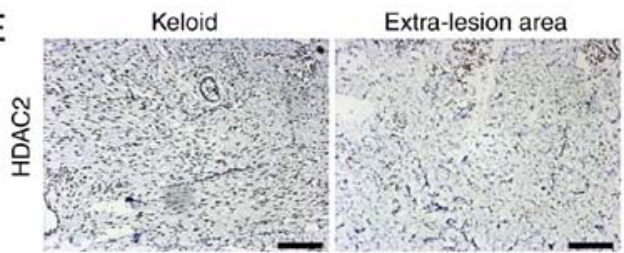

B
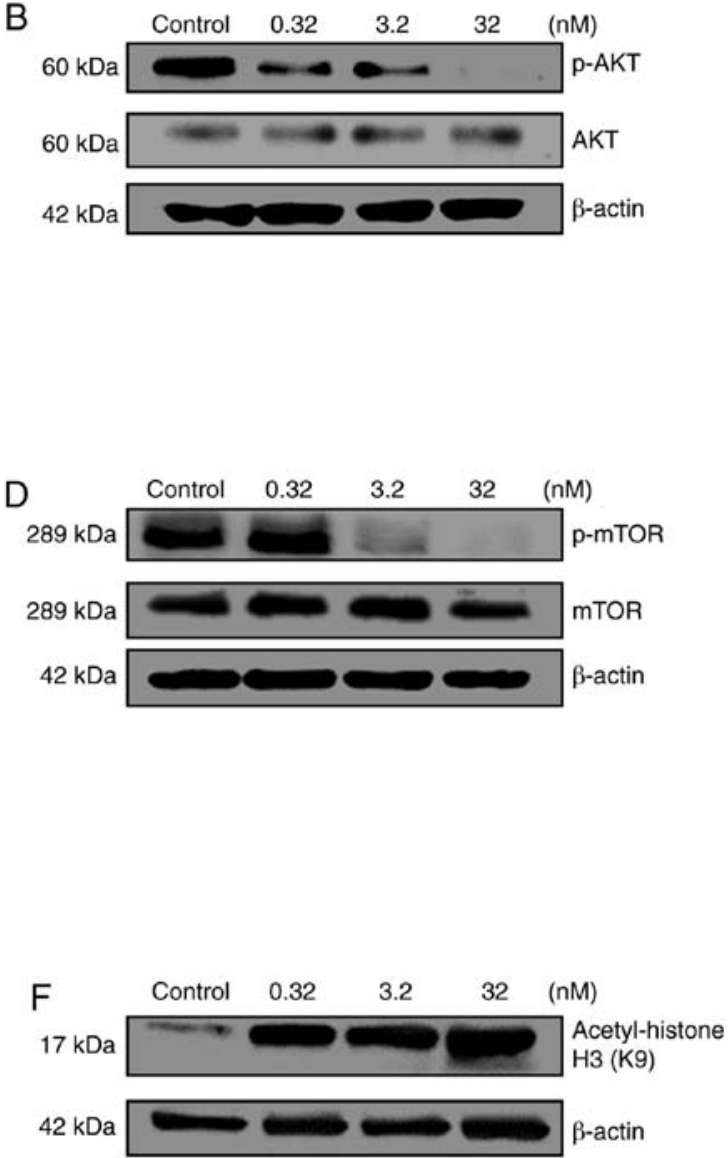

Figure 1. Enhanced PI3K/Akt/mTOR signaling pathway and HDAC2 expression in keloids and the inhibitory effect of CUDC-907. (A) Enhanced expression of AKT protein and its elevated phosphorylation level in keloid compared with the levels of extra-lesion tissue. (B) Inhibitory effect of CUDC-907 on AKT phosphorylation in keloid fibroblasts. (C) Enhanced phosphorylation of mTOR in keloid compared with that of extra-lesion tissue. (D) Inhibitory effect of CUDC-907 on mTOR phosphorylation in keloid fibroblasts. (E) Enhanced expression of HDAC2 in keloid compared to that of extra-lesion tissue (F) Promotive effect of CUDC-907 on acetylation of Histone H3 in keloid fibroblasts. Magnification, x100. Scale bar=200 $\mu \mathrm{m}$. PI3K/Akt/mTOR, phosphoinositide 3-kinase/RAC-alpha serine/threonine-protein kinase/mammalian target of rapamycin; p, phosphorylated; HDAC2, Histone deacetylases 2.

CUDC-907 inhibits the PI3K/Akt/mTOR signaling pathway and promotes acetylation of histone H3. Following the retreatment with CUDC-907 for $72 \mathrm{~h}$, Akt phosphorylation was significantly inhibited, particularly at the concentrations of 3.2 and $32 \mathrm{nM}$ (Fig. 1B). Similarly, phosphorylation of mTOR was also significantly inhibited at a concentration of $32 \mathrm{nM}$ (Fig. 1D). With the increased concentrations of CUDC-907, the acetylation level of histone $\mathrm{H} 3$ gradually increased with a marked dose-dependent pattern (Fig. 1F).

CUDC-907 suppresses KF proliferation and induces $G 2-M$ cell cycle arrest. CUDC-907 significantly decreased the proliferation of KFs in a dose-dependent manner (Fig. 2A). In addition, the dual inhibitor CUDC-907 was markedly more potent compared with GDC-0941, a PI3K/Akt/mTOR inhibitor, and trichostatin A, a HDAC inhibitor, following drug treatment for 7 days (Fig. 2B).

Cell cycle analysis suggested marked G2/M arrest, which was expressed as a dose-dependent decrease in the percentage of G0/G1 phase cells and a corresponding dose-dependent increase in the percentage of cells in $G 2 / \mathrm{M}$ phase $(P<0.05$; Fig. 2C and D).
Results of qPCR and western blot analysis further validated this observation (Fig. 2E and F). At both mRNA and protein levels, enhanced expression of cyclin-dependent kinase inhibitor $1(\mathrm{p} 21)(\mathrm{P}<0.05)$, steadily expressed $\mathrm{p} 53$ $(\mathrm{P}>0.05)$ and attenuated cyclin $\mathrm{B}$ expression $(\mathrm{P}<0.05)$ were observed following drug treatment with a dose-response pattern.

CUDC-907 inhibits migratory capacity of KFs. At both 24 and $48 \mathrm{~h}$ after the scratch assay, a significant dose-dependent inhibitory effect on migration was observed $(\mathrm{P}<0.05$ : Fig. $3 \mathrm{~A}$ and D). In the Transwell migration assay, after $24 \mathrm{~h}$ of drug treatment, the number of migrated cells on the bottom surface of the top chamber was significantly decreased with the increasing drug concentrations, in a dose-dependent manner (Fig. 3B). Semi-quantitative analysis indicated decreased cell numbers with significant differences between treatment groups $(\mathrm{P}<0.05$; Fig. 3E).

In addition, as demonstrated in Fig. 3C, decreased numbers of the cells in the migration zone were observed following increasing concentrations of CUDC-907, in a dose-dependent pattern after $24 \mathrm{~h}$ drug treatment $(\mathrm{P}<0.05$; Fig. $3 \mathrm{C}$ and $\mathrm{F})$. 

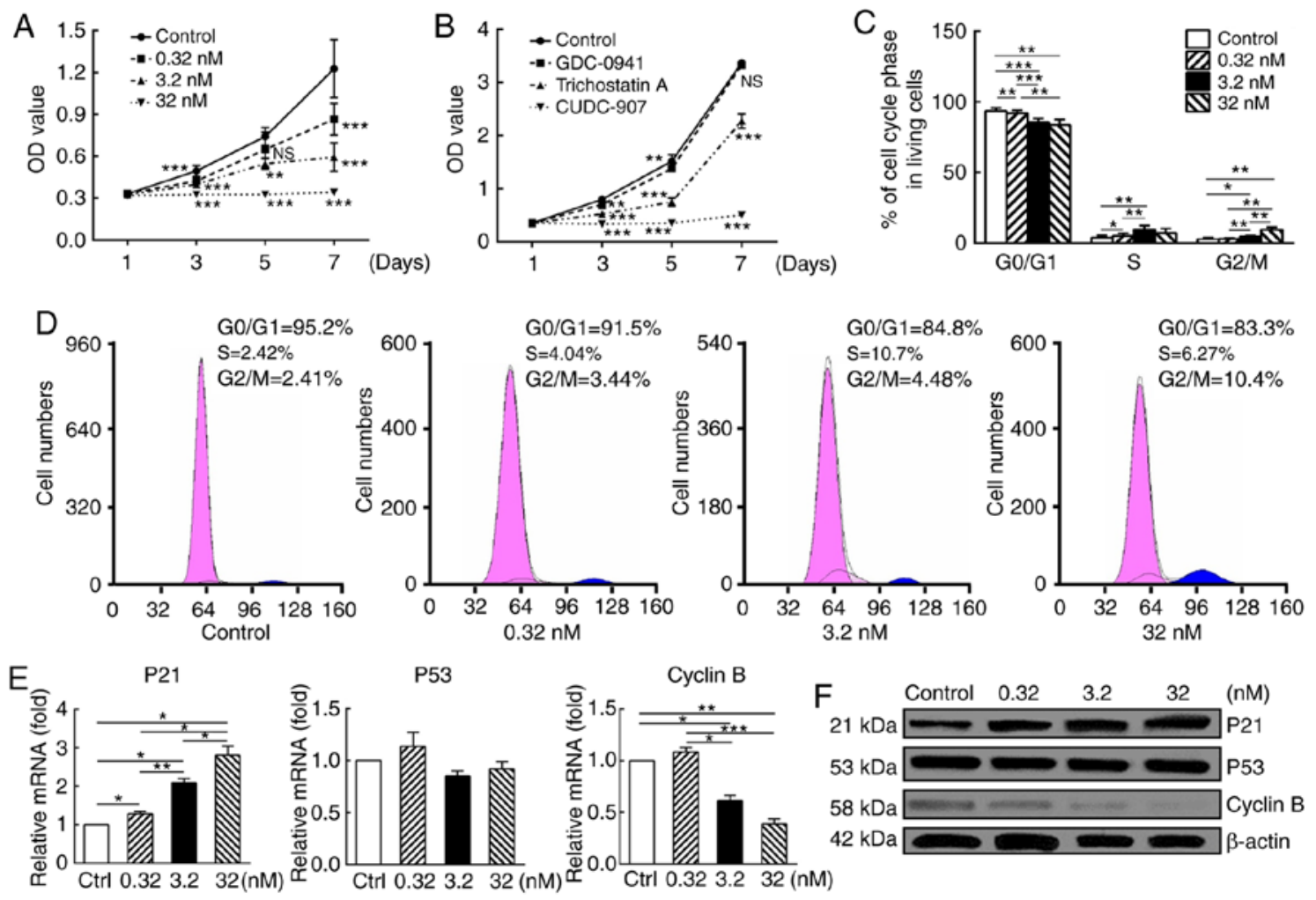

Figure 2. CUDC-907 suppresses proliferation and induces G2/M cell cycle arrest in treated keloid fibroblasts. (A) Cell Counting Kit-8 analysis revealed that cell proliferation was inhibited by CUDC-907 at different concentrations, with significant differences among treatment groups. (B) CUDC-907 exerted a more marked inhibitory effect on keloid fibroblast proliferation compared with GDC-0914 and trichostatin A at the same concentration of $32 \mathrm{nM}$. (C) Flow cytometry analysis demonstrated a G2-M phase cell cycle arrest after 5-day exposure to CUDC-907, with significant differences among treatment groups. (D) Representative cell cycle data were plotted for each group. (E) Gene expression level (treated for $72 \mathrm{~h}$ ) and (F) protein expression (treated for $16 \mathrm{~h}$ ) analyses revealed increased p21, decreased cyclin B and unaltered p53 expression levels, and significant differences among groups were indicated with error bars representing standard error of the mean. All experiments were repeated in at least 3 cell samples. ${ }^{*} \mathrm{P}<0.05,{ }^{* *} \mathrm{P}<0.01$ and ${ }^{* * * *} \mathrm{P}<0.001$. p21, cyclin-dependent kinase inhibitor 1; O.D., optical density.

CUDC-907 inhibits the invasive capabilities of KFs. The aforementioned Transwell system was also used to measure the invasive capabilities of KFs. As indicated in Fig. 3B and E, KFs in the control group successfully passed through the Matrigel to the bottom surface of the top chamber. Conversely, relatively fewer cells in the CUDC-907 treatment groups successfully invaded through Matrigel $(\mathrm{P}<0.05)$. Analogous results were also observed in an assay conducted with an Oris ${ }^{\mathrm{TM}}$ invasion kit, but with the inclusion of a collagen gel. As demonstrated in Fig. 3C and F, a decrease in cell numbers in the detection zone was observed with the increasing drug concentrations $(\mathrm{P}<0.05)$. In addition, matrix metalloproteinases (MMPs) and tissue inhibitor of metalloproteinases (TIMPs) serve an important role in invasion ability of tumor cells (28). Decreased MMP/TIMP1 gene expression ratios, concomitant with increased drug concentrations, were observed in MMP1/TIMP1, MMP2/TIMP1, MMP3/TIMP1 and MMP13/TIMP1 (P<0.05; Fig. 3G).

CUDC-907 attenuates collagen expression and production of cultured KFs in vitro and keloid tissue ex vivo. As demonstrated in Fig. 4A, at an mRNA level, CUDC-907 treatment significantly downregulated the expression of collagen I (COL1) and collagen III (COL3) $(\mathrm{P}<0.05)$ at the concentrations of 3.2 and $32 \mathrm{nM}$, but not at $0.32 \mathrm{nM}(\mathrm{P}>0.05)$. Expression levels of these genes in the KFs treated with GDC-0941, a PI3K/Akt/mTOR inhibitor, or trichostatin A, a HDAC inhibitor, at $32 \mathrm{nM}$ were not identified to be significantly different from those of control (P>0.05; Fig. 4B), but were significantly increased compared with that of the CUDC-907-treated cells $(\mathrm{P}<0.05)$. In contrast to the KFs, the normal dermal fibroblasts were identified to be less sensitive to CUDC-907 treatment, indicating a cell type-specific inhibitory effect of CUDC-907 (Fig. 4C).

Concomitantly, the results from the western blot analysis also suggested significantly decreased protein production of COL1 and COL3 following CUDC-907 treatment (Fig. 4D). Furthermore, immunohistochemical staining of the keloid tissue explant also exhibited decreased COL1 and COL3 production, due to the treatment of CUDC-907 (Fig. 5A), particularly at $32 \mathrm{nM}(\mathrm{P}<0.05$; Fig. 5B).

CUDC-907 attenuates TGF- $\beta 1$ production and signaling. At the mRNA level, CUDC-907 treatment for $72 \mathrm{~h}$ significantly downregulated the expression of TGF- $\beta 1$ at the concentrations of 3.2 and $32 \mathrm{nM}(\mathrm{P}<0.05)$ but not at $0.32 \mathrm{nM}(\mathrm{P}>0.05)$ (Fig 4A). Western blot analysis indicated that CUDC-907 treatments at 3.2 and $32 \mathrm{nM}$ significantly inhibited the phosphorylation of Smad2/3, whereas the reduction of Erk phosphorylation was only observed at the concentration of $32 \mathrm{nM}$, as demonstrated in Fig. 4E.

CUDC-907 inhibits angiogenesis in keloid tissue explant ex vivo. Excessive vascularization following trauma is another important pathogenic factor underlying keloid formation (29). 
A
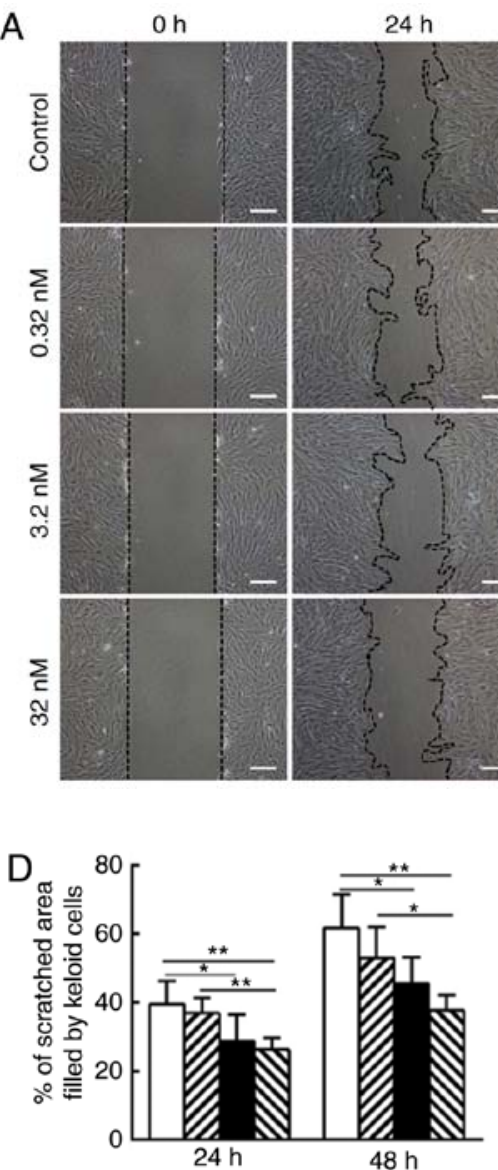

$24 \mathrm{~h}$

$48 \mathrm{~h}$

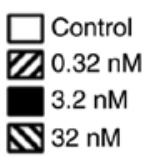

$24 \mathrm{~h}$
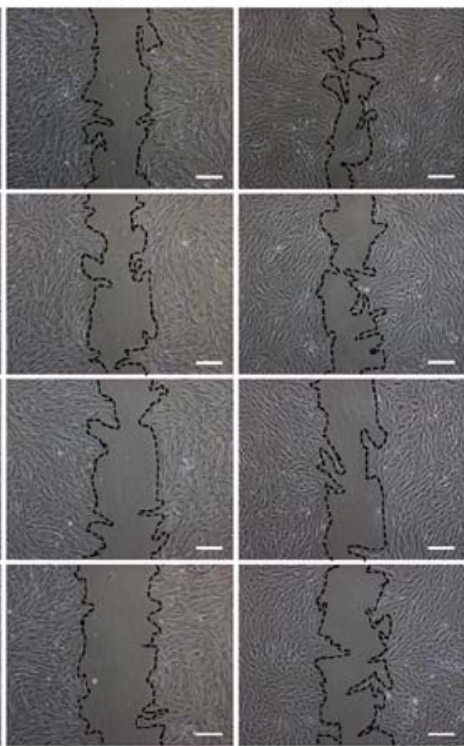

E
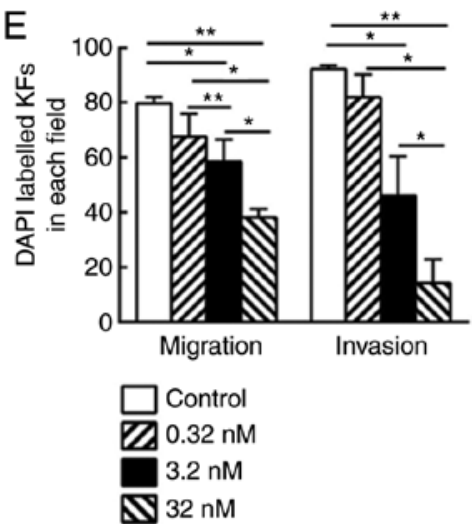

B

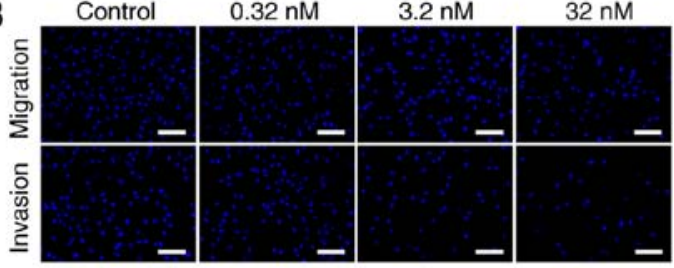

C Control

$0.32 \mathrm{nM}$

$3.2 \mathrm{nM}$

$32 \mathrm{nM}$

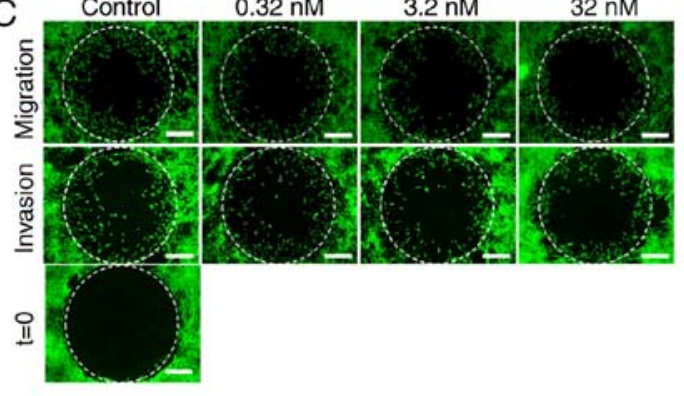

G
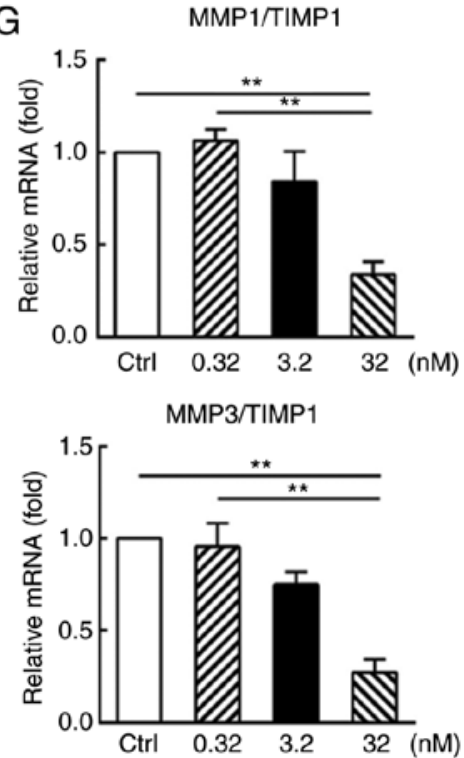

$\mathrm{F}$

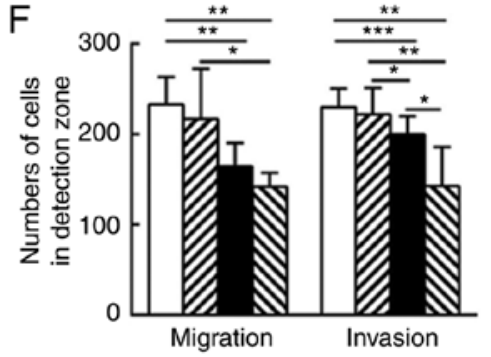

$\square$ Control

$\square 0.32 \mathrm{nM}$

$3.2 \mathrm{nM}$

$\mathbf{\Delta} 32 \mathrm{nM}$

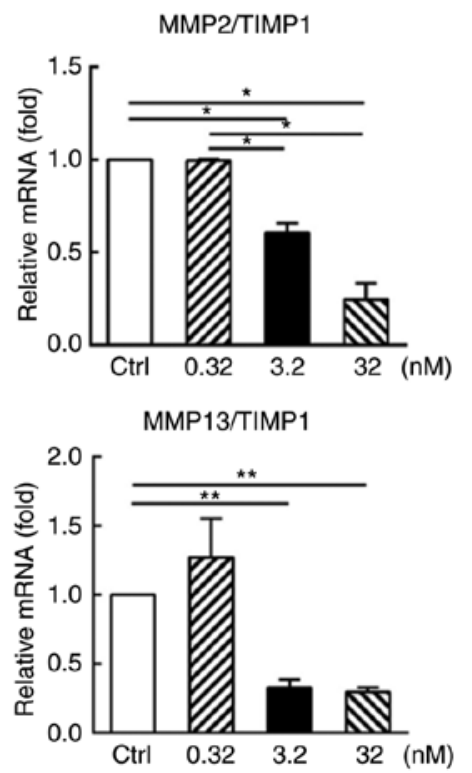

Figure 3. CUDC-907 inhibits the migratory and invasive capabilities of cultured keloid fibroblasts. (A) Inhibited cell migration at 24 and $48 \mathrm{~h}$ post-treatment in the scratch assay. (B) Inhibited cell migration and invasion in a Transwell migration/invasion assay at $24 \mathrm{~h}$ post-treatment as revealed by decreased DAPI labelled cells that migrated through the porous membrane. (C) Inhibited cell migration in an Oris ${ }^{\mathrm{TM}}$ migration/invasion system at 24 and $48 \mathrm{~h}$ post-treatment, respectively, as demonstrated by decreased numbers of the cells in the detection zone. (D) Semi-quantitative analysis of the scratch assay results ( $\mathrm{n}=20$ ). (E) Semi-quantitative analysis of the Transwell migration and invasion assay results $(n=15)$. (F) Semi-quantitative analysis of the Oris ${ }^{\mathrm{TM}}$ migration and invasion assay results $(\mathrm{n}=20)$. All experiments were repeated in at least triplicated cell samples and 5 fields in each cell samples were randomly selected for statistical analysis. (G) Quantitative polymerase chain reaction analysis revealed decreased MMPs/TIMP1 gene expression ratios concomitant with increased drug concentrations. This assay was performed 3 times in 3 different cell samples. Data are presented as the mean \pm standard error of the mean. ${ }^{*} \mathrm{P}<0.05$ and ${ }^{* *} \mathrm{P}<0.01$. MMP, matrix metalloproteinase; TIMP, tissue inhibitor of metalloproteinase. 
A

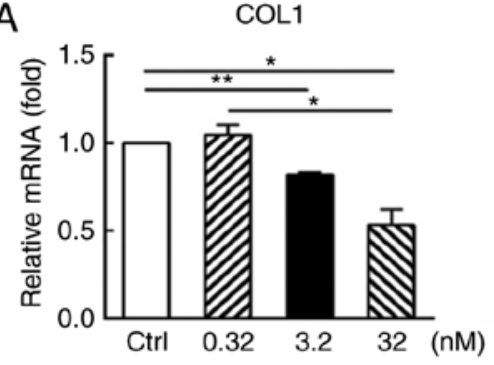

B

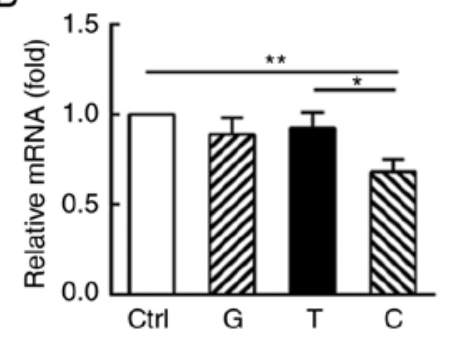

C

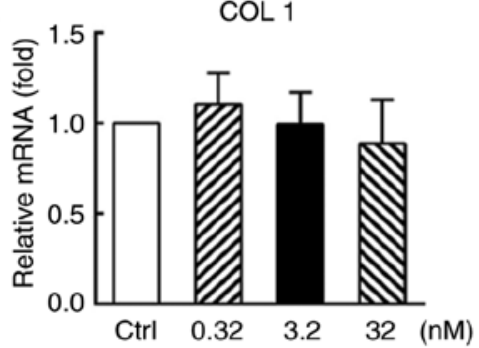

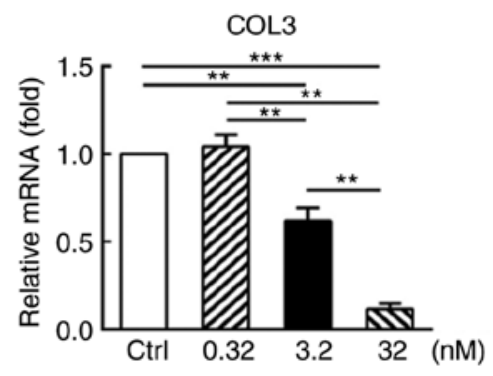

COL 3

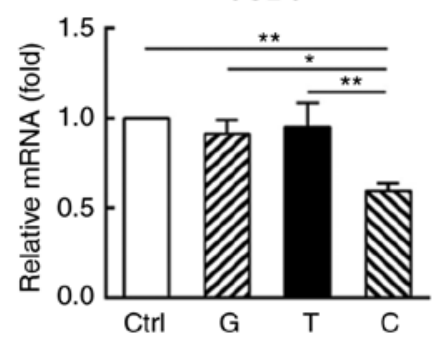

$\mathrm{COL} 3$

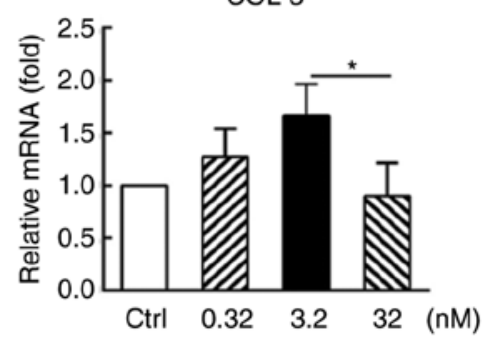

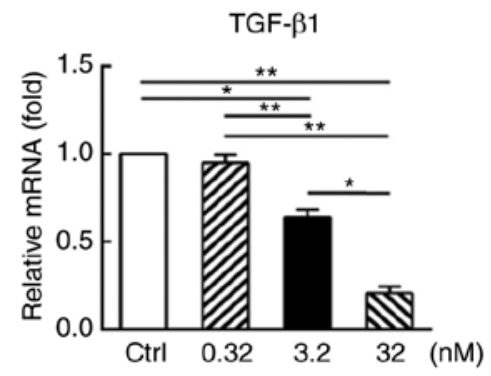

TGF- $\beta 1$

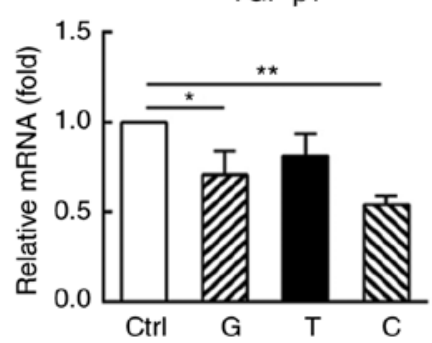

TGF- $\beta 1$

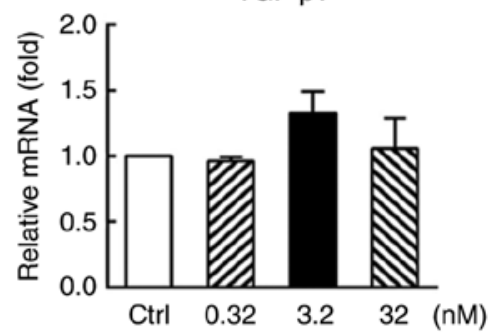

E

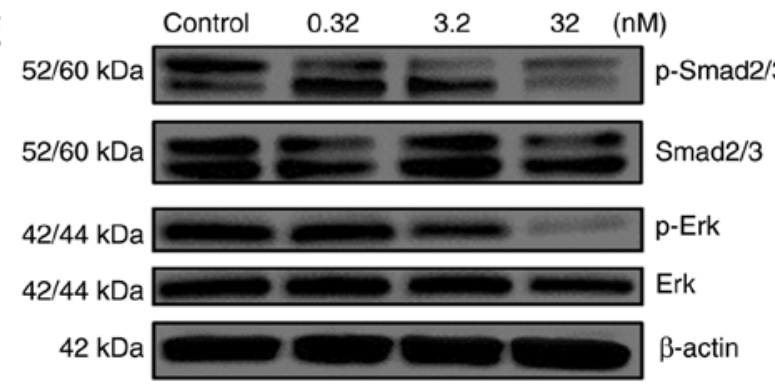

Figure 4. CUDC-907 decreases collagen expression or production of in vitro cultured keloid fibroblasts along with attenuated Smad and Erk phosphorylation. (A) After $72 \mathrm{~h}$ CUDC-907 treatment, KFs expressed decreased levels of COL1, COL3 and TGF- $\beta 1$ at transcriptional level with significant differences among the treatment groups. (B) Inhibitory effects of GDC-0941, trichostatin A and CUDC-907 on the gene expression levels of COL1, COL3 and TGF- $\beta 1$ at $32 \mathrm{nM}$ for $72 \mathrm{~h}$. (C) No significant inhibitory effect of CUDC-907 on COL1, COL3 and TGF- $\beta 1$ gene expression levels of normal dermal fibroblasts was observed after $72 \mathrm{~h}$ from the treatment. (D) CUDC-907 treatment decreased the production of COL1 and COL3 at $72 \mathrm{~h}$ post-treatment, as demonstrated by western blot analysis. (E) CUDC-907 also attenuated the phosphorylation levels of Smad 2/3 and Erk of the keloid fibroblasts treated with various concentrations of CUDC-907 at $72 \mathrm{~h}$ post-treatment. The assays were repeated 3 times with 3 independently pooled cell samples. Data are presented as the mean \pm standard error of the mean. ${ }^{*} \mathrm{P}<0.05,{ }^{* *} \mathrm{P}<0.01$ and ${ }^{* * * *} \mathrm{P}<0.001$. COL1, collagen I; COL3, collagen III; TGF- $\beta 1$, transforming growth factor $\beta 1 ;$, phosphorylated; G, GDC-0941; T, trichostatin A; C, CUDC-907.

As indicated in Fig. 5C, the number of blood vessels marked with CD31 and CD34, two common immunohistochemical markers of endothelial cells (30), gradually decreased as the concentration of CUDC-907 increased ( $\mathrm{P}<0.05$; Fig. 5D). As a confirmation of this observation, CUDC-907 treatment significantly disrupted vessel tube formation mediated by HUVECs in vitro (Fig. 5E and G).

CUDC-907 suppresses KF migration and proliferation in cultured keloid explants ex vivo. As demonstrated in Figs. $5 \mathrm{~F}$ and S1, KFs with a spindle shape migrated out from the edges of the explanted tissue and gradually filled the Petri dish over 1 week via cell migration and proliferation. CUDC-907 treatment for 7 days significantly decreased the number of cells migrating from the keloid explants. The inhibitory effect became more significant with the increasing drug concentrations $(\mathrm{P}<0.05$; Fig. $5 \mathrm{H})$.

CUDC-907 attenuates collagen deposition and angiogenesis in a keloid xenograft model. At the 10th and the 20th day of CUDC-907 administration, xenografts on the backs of nude mice had not decreased nor increased in size consistently 
A
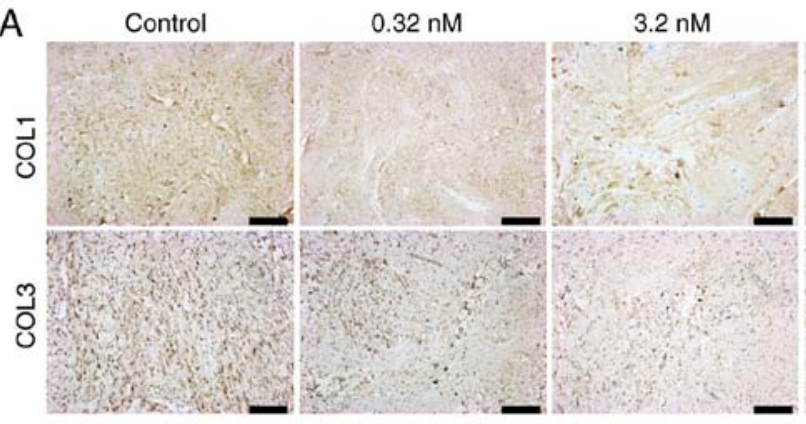

C

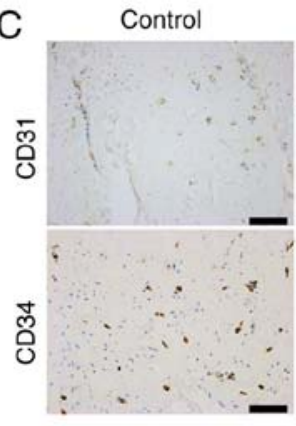

E

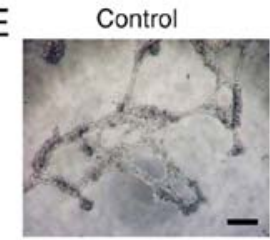

$\mathrm{F}$

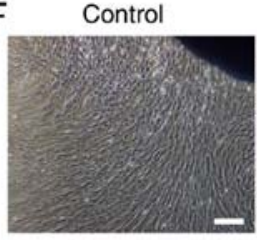

$0.32 \mathrm{nM}$

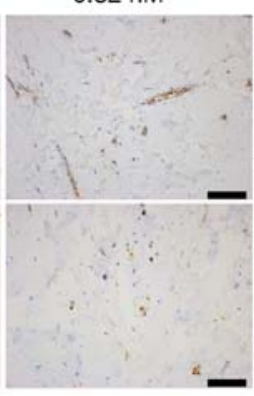

$0.32 \mathrm{nM}$

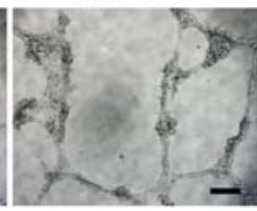

$0.32 \mathrm{nM}$

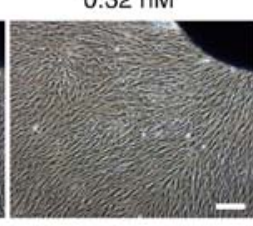

$3.2 \mathrm{nM}$

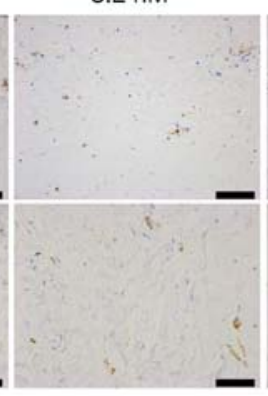

$3.2 \mathrm{nM}$

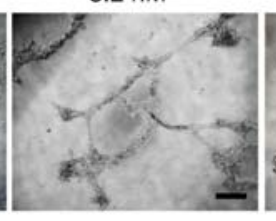

$3.2 \mathrm{nM}$

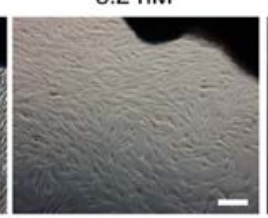

32 nM

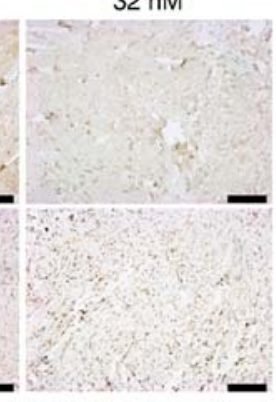

$32 \mathrm{nM}$

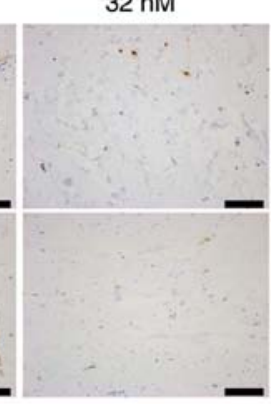

$32 \mathrm{nM}$

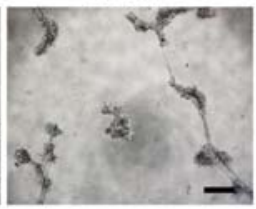

$32 \mathrm{nM}$

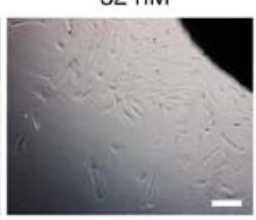

B
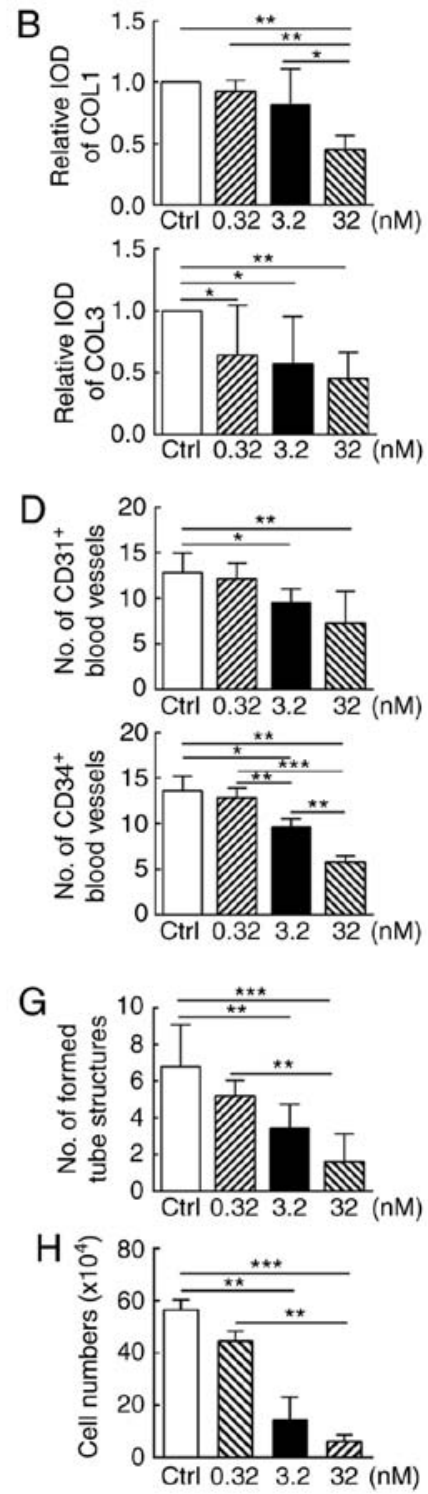

Figure 5. CUDC-907 decreases collagen accumulation and microvessels in cultured keloid tissue explant. (A) Deposition of COL1 and COL3 was apparently inhibited in the tissue explants following increased drug concentrations. Magnification, $x 100$; scale bar=200 $\mu \mathrm{m}$. (B) Semi-quantitative analysis of collagen deposition of immunohistochemically stained tissue sections $(n=20)$. Data are presented as the mean \pm standard deviation of the mean. $(C) C D 31^{+}$and $C D 34^{+}$ stained microvessels were apparently disrupted and decreased in number with increasing drug concentrations. Magnification, $\mathrm{x} 200$; scale bar $=100 \mu \mathrm{m}$. (D) Semi-quantitative analysis of microvessel numbers in the immunohistochemically stained tissue sections ( $\mathrm{n}=20$ ). The assays were performed 3 times with 3 independent tissue samples and semi-quantitative analysis was performed based on 5 randomly selected fields of each tissue sample. Data are presented as the mean \pm standard deviation of the mean. (E) CUDC-907 inhibited spontaneous tube formation mediated by human umbilical vein endothelial cells. Experiments were repeated 5 times. Magnification, $\mathrm{x} 40$; scale bar $=250 \mu \mathrm{m}$. (F) Representative images of tissue explants (black shadows in the upper right comers) cultured without or with different concentrations of the CUDC-907 at day 7 post-treatment. Magnification, $\mathrm{x} 40$; scale bar=250 $\mu \mathrm{m}$. (G) The numbers of formed tube cultured under different concentrations of the drug were manually counted in 5 replicates for each treatment group. Data are presented as the mean \pm standard deviation. $(\mathrm{H})$ Cells were collected from each group of cultured tissue explants at day 7 and the cell numbers are presented in the bar graph. ${ }^{*} \mathrm{P}<0.05,{ }^{* *} \mathrm{P}<0.01$ and ${ }^{* * *} \mathrm{P}<0.001$.

(Fig. 6A and B). However, at the histological level, decreased cell density, COL1 and COL3 deposition, CD31 ${ }^{+}$and $\mathrm{CD} 34^{+}$ blood vessels were observed in the keloid xenograft by hematoxylin and eosin or immunohistochemical staining, which suggested that CUDC-907 was able to exert its anti-fibrosis and anti-angiogenesis effects in vivo (Fig. 6C and D).

\section{Discussion}

Keloid is a tumor-like skin disorder unique to humans, which is commonly observed in those of African and Asian descent, with neoplasms growing beyond the wound boundary but never metastasizing to distant sites (31). Different from normal scars, an excessive inflammatory response, unrestricted angiogenesis and collagen accumulation are present during the whole process during keloid formation, which may lead to intolerable pruritus, pain and even disfigurement (21). Due to the high recurrence rate following keloid excision, a classic anti-keloid drug, 5-Fluorouracil, was generally utilized as an auxiliary chemotherapy after surgical procedures (32). Although a diverse range of small molecule compounds have been developed in order to improve the clinical outcome of 


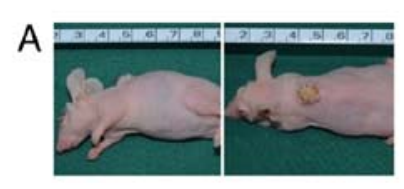

B

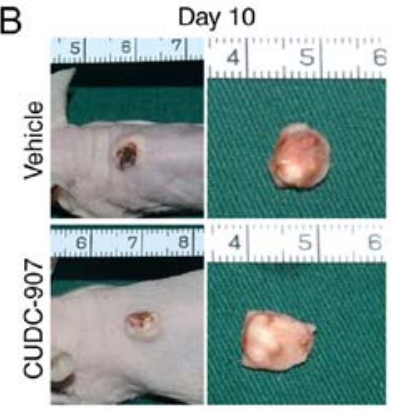

Day 20
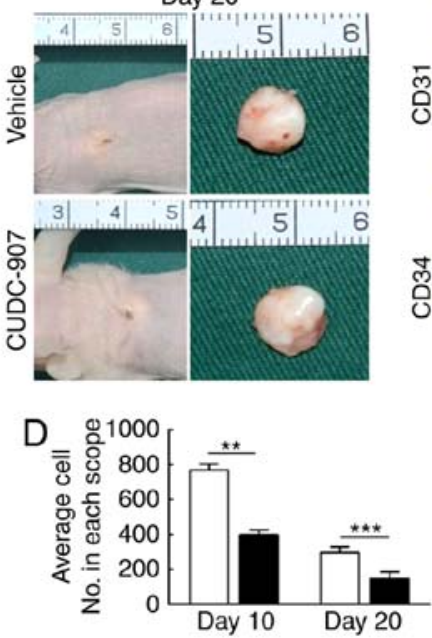

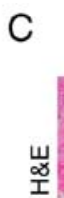

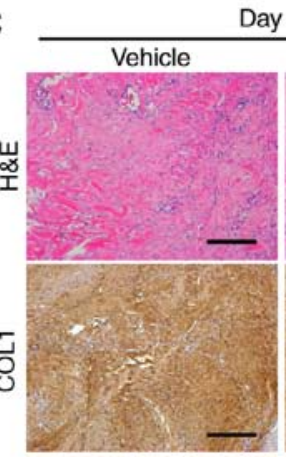

Day 10
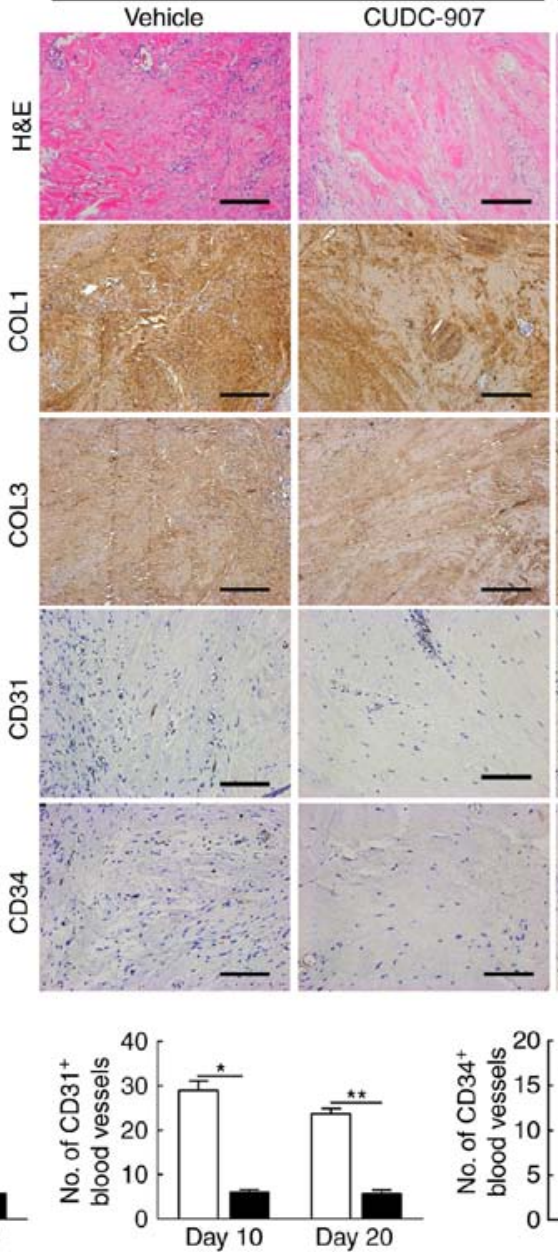

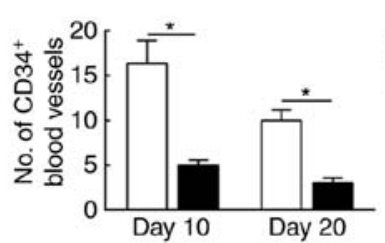

Day 20

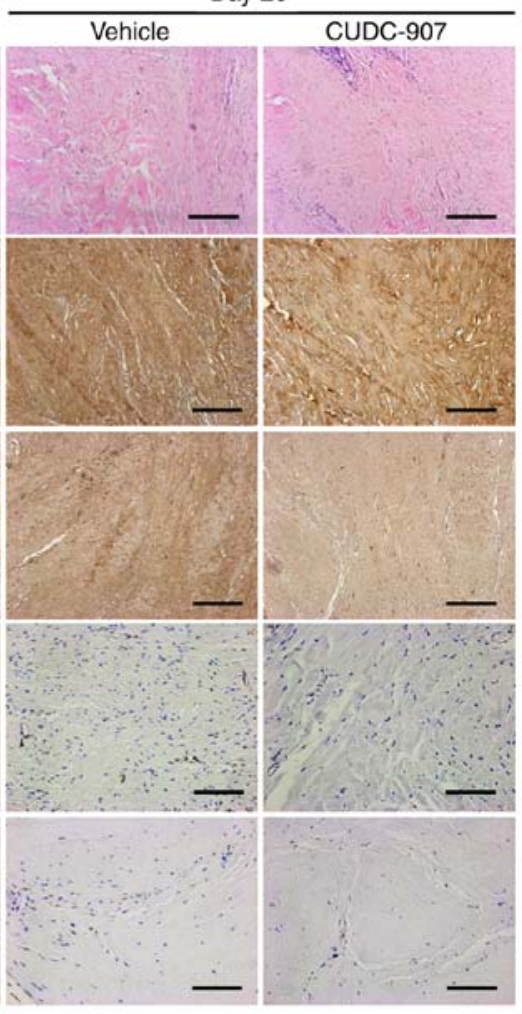

Vehicle

CUDC-907

Figure 6. CUDC-907 decreases cell density, collagen deposition and angiogenesis of keloid xenografts in a nude mouse model. (A) A cylindrical epidermis-intact keloid xenograft (diameter $=8 \mathrm{~mm}$ ) was attached to the back of nude mice. (B) At the 10th and the 20th day after intra-tissue drug administration, tissue samples were harvested. (C and D) Hematoxylin and eosin and immunohistochemical staining revealed fewer cell numbers, decreased deposition of COL1 and COL3 and fewer formed microvessels ( $\mathrm{n}=15$ ). Magnification, $\mathrm{x} 200$; scale bar $=250 \mu \mathrm{m}$. Data are presented as the mean \pm standard deviation of the mean. "P<0.05, ${ }^{* *} \mathrm{P}<0.01$ and ${ }^{* * *} \mathrm{P}<0.001$. COL1, type I collagen; COL3, type III collagen; CD31, platelet endothelial cell adhesion molecule; CD34, hematopoietic progenitor cell antigen CD34.

keloid therapy, their low efficacy and multiple adverse side effects demand more advanced solutions and the identification of a compound that precisely targets the vital elements of keloid growth (33).

The occurrence of keloids cannot be attributed to any known single predisposing factor. In fact, ethnicity or genetic background, immune dysfunction, abnormal fibroblasts and other extrinsic stimuli like tension and infection may all be associated with keloid formation $(31,34)$. Among multiple pathological elements, abnormality of KFs serves a significant role in the pathogenesis, including hyperproliferation, aberrant capacity of migration and invasion, excessive production and deposition of extracellular matrices (35). Notably, certain small chemical compounds developed for anti-tumor treatment were demonstrated to have similar mechanism of action to keloid chemotherapy $(36,37)$. Studies investigating the mechanisms of these compounds may also contribute to the understanding of keloid pathogenesis and subsequently to the development of anti-keloid compounds.

The involvement of PI3K/AKT/mTOR signaling and HDAC in the abnormal functions of keloid cells has been previously described $(9,11,14)$. Single-target inhibitors of either the PI3K/Akt/mTOR pathway or HDACs would be good drug candidates for keloid therapy, but their demonstrated low efficacies have limited their potential in clinical application. Inhibition of the PI3K pathway alone did not work as well as expected due to adverse activation of other tumor-associated signaling pathways or drug-resistance $(38,39)$. Similarly, trichostatin A, a previously described anti-keloid HDAC inhibitor, effectively inhibited the proliferation and collagen production of KFs at relatively higher concentrations (9), leading to increasing potential risk in its further clinical application. To lower this potential risk, a feasible solution would be to identify a compound that has multiple targets and may achieve a satisfactory therapeutic effect with minimal doses via a synergistic effect across the multiple targets (40).

It has been demonstrated that drugs that simultaneously suppressed both HDAC and PI3K exhibited improved function compared with single HDAC inhibitors for the treatment of cutaneous T-cell lymphoma or other types of cancer $(41,42)$. In addition, it is difficult for a hybrid molecule like CUDC-907 to escape from cells following conversion 
into pharmacologically active acid form, easily increasing the levels of intracellular accumulation (43). In the present study, 3 concentrations of $0.32,3.2$ and $32 \mathrm{nM}$ were selected based on extensive pre-experimental screening and previous data (18). It should be noted that the concentrations used in the present study were much lower compared with the single-target inhibitors investigated in previous studies $(8,9,11)$. The inhibitory effect of CUDC-907 on the hyperproliferation of KFs was observed even at the lowest concentration $(0.32 \mathrm{nM})$. At higher concentrations (3.2 and $32 \mathrm{nM}$ ), the drug potently suppressed the migratory and invasive capabilities of KFs, decreased the excessive production of collagen, and prevented excessive angiogenesis. In addition, by comparing the inhibitory effect of CUDC-907 with GDC-0941 and trichostatin $\mathrm{A}$ at $32 \mathrm{nM}$, it was confirmed that the CUDC-907-mediated inhibition of cell proliferation and collagen production in KFs was improved compared with GDC-0941 and trichostatin A. The present study demonstrated that CUDC-907 exhibited a more potent inhibitory effect compared with either trichostatin A or GDC-904 alone on cell proliferation and collagen gene expression, indicating that CUDC-907 exerted the synergistic effect of dual signaling inhibition and therefore may be a more potent targeted drug for keloid therapy.

Such phenomena were also described in previous studies (44). Different anti-proliferative mechanisms of mTOR or HDAC inhibitors were demonstrated $(11,45-48)$, but another previous study revealed that CUDC-907 induced a G2/M cell cycle arrest of H460, a human tumor cell line (18), indicating that CUDC-907 may interfere with the cell mitosis process. In fact, $\mathrm{G} 2 / \mathrm{M}$ arrest in other tumor cell lines resulting from the treatment with several kinds of HDAC inhibitors has been observed (49). Although no significant differences were detected in p53 expression levels at the concentrations used in the present study, a significant increase in p21 expression levels [also identified previously (18)], has been established to be a definite result of inhibition of either the PI3K/Akt/mTOR or HDACs pathways $(50,51)$. In addition, inhibitors targeting any one of these signaling pathways may also downregulate the levels of cyclin B, resulting in a G2/M arrest $(52,53)$. The HDAC inhibitor valproic acid downregulated the levels of cyclin B and even demonstrated a sensibilization effect on rapamycin, a classic mTOR inhibitor, indicating the synergistic effect between inhibition of the PI3K/Akt/mTOR pathway and HDACs (53).

The attenuated ability of cell migration and invasion in KFs is also associated with the inhibition of the PI3K pathway and HDACs $(49,54)$. To be specific, the HDAC1 inhibitor, largazole, was previously confirmed to be capable of suppressing the migration of a human microvascular endothelial cell line (55). Bian et al (56) identified that the multiple anticancer effects of HDAC inhibitors were achieved partially by upregulating miR-200c and thereby decreasing Crk-like protein. However, the vital mechanism has not been fully understood yet. Furthermore, the drug treatment also altered MMP expression levels in the present study; measuring the activities of MMP will provide a more accurate reflection of the cellular functions.

Functional alterations following the abrogation of exogenous TGF- $\beta 1$ by inhibition of the PI3K/Akt/mTOR pathway or HDACs have been investigated previously $(57,58)$, but the present study provided evidence that the dual inhibition of the PI3K/Akt/mTOR pathway and HDACs decreased the expression levels of endogenous TGF- $\beta 1$. The decrease of gene expression of $T G F-\beta 1$ and the inhibition of its downstream cascade may provide an explanation why CUDC-907 exhibited such potent anti-fibrotic capacity $(59,60)$. Although the activation of PI3K/Akt pathway alone was insufficient to upregulate collagen, type I, alpha 2 gene transcription, its activation triggered by TGF- $\beta 1$ may enhance Smad3 transcriptional activity, leading to increased COL1 expression (36). Decreased phosphorylation of Erk, which may be activated simultaneously along with the PI3K pathway in KFs, also provided an explanation of how CUDC-907 attenuated collagen production (61). A previous study suggested that a HDAC inhibitor was able to counteract exogenous TGF- $\beta 1$ and thereby suppress collagen deposition in KFs (8), which was in concordance with the results of the present study.

To further investigate the potential effects of CUDC-907 treatment in a clinical setting, an in vivo xenograft model was employed in the present study. The implanted xenograft did not grow following implantation, and therefore no significant differences in tissue volume were observed. However, significant differences were identified in matrix deposition and in microvessel structure integrity. Therefore, the in vivo model also supports the conclusions of the in vitro assays.

In summary, the present study confirmed that the efficient inhibition of both the PI3K/Akt/mTOR pathway and HDACs activity by CUDC-907 led to significant inhibition of pathological cell proliferation, collagen production and ECM deposition, and the cellular migratory and invasive capabilities, in addition to the angiogenic process of keloids. As all of these factors are the key contributors to keloid formation, the results of the present study described the great therapeutic potential of CUDC-907 for keloid clinical therapy in the future.

\section{Acknowledgements}

The authors would like to acknowledge the technical support of Dr Wanyao Xia, Dr Lijuan Zong, Dr Juanjuan Wu and Dr Junhong Lu from Shanghai Key Laboratory of Tissue Engineering. In addition, the authors would like to thank Mr. Haibo Li of Xiangya School of Medicine, Central South University for assistance with image acquisition.

\section{Funding}

The present study was financially supported by China National Nature Science Foundation (grant no. 81671921).

\section{Availability of data and materials}

The datasets used and/or analyzed during the current study are available from the corresponding author on reasonable request.

\section{Authors' contributions}

TT drafted experiment design and conducted the experiments. $\mathrm{JH}$ and ML performed the primary keloid fibroblasts culture and tissue explant handling. ZG and XW provided tissue samples and contributed to critical evaluation of samples, and provided 
guidance for the handling of the keloid tissues. WZ and GZ revised the experimental design and provided technical support. WW and WL are responsible for revising the manuscript critically for important intellectual content and manuscript editing. All authors read and approved the final manuscript.

\section{Ethics approval and consent to participate}

Protocols for the handling of human tissues and cells were approved by the Ethics Committee of Shanghai Ninth People's Hospital. All protocols concerning animal experiments were approved by the Animal Care and Welfare Committee of Shanghai Ninth People's Hospital. All involved patients provided written informed consent.

\section{Patient consent for publication}

All patients provided written informed consent.

\section{Competing interests}

The authors declare that they have no competing interests.

\section{References}

1. Ghazawi FM, Zargham R, Gilardino MS, Sasseville D and Jafarian F: Insights into the pathophysiology of hypertrophic scars and keloids: How do they differ? Adv Skin Wound Care 31: 582-595, 2018

2. Morelli Coppola M, Salzillo R, Segreto F and Persichetti P: Triamcinolone acetonide intralesional injection for the treatment of keloid scars: Patient selection and perspectives. Clin Cosmet Investig Dermatol 11: 387-396, 2018.

3. Forbat E, Ali FR and Al-Niaimi F: Treatment of keloid scars using light-, laser- and energy-based devices: A contemporary review of the literature. Lasers Med Sci 32: 2145-2154, 2017.

4. Russell SB, Trupin KM, Rodriguez-Eaton S, Russell JD and Trupin JS: Reduced growth-factor requirement of keloid-derived fibroblasts may account for tumor growth. Proc Natl Acad Sci USA 85: 587-591, 1988

5. Vincent AS, Phan TT, Mukhopadhyay A, Lim HY, Halliwell B and Wong KP: Human skin keloid fibroblasts display bioenergetics of cancer cells. J Invest Dermatol 128: 702-709, 2008.

6. Zhang Q, Yamaza T, Kelly AP, Shi S, Wang S, Brown J, Wang L, French SW, Shi S and Le AD: Tumor-Like stem cells derived from human keloid are governed by the inflammatory niche driven by IL-17/IL-6 axis. PLoS One 4: e7798, 2009.

7. Jumper N, Paus R and Bayat A: Functional histopathology of keloid disease. Histol Histopathol 30: 1033-1057, 2015.

8. Syed F, Sherris D, Paus R, Varmeh S, Pandolfi PP and Bayat A: Keloid disease can be inhibited by antagonizing excessive mTOR signaling with a novel dual TORC $1 / 2$ inhibitor. Am J Pathol 181: 1642-1658, 2012.

9. Diao J, Xia W, Yi C, Wang Y, Li B, Xia W, Liu B, Guo S and Sun X: Trichostatin A inhibits collagen synthesis and induces apoptosis in keloid fibroblasts. Arch Dermatol Res 303: 573-580, 2011.

10. Yi D, Bihl J, Newman MS, Chen Y and Simman R: The preliminary study of effects of tolfenamic acid on cell proliferation, cell apoptosis, and intracellular collagen deposition in keloid fibroblasts in vitro. Dermatol Res Pract 2014: 1-8, 2014.

11. Syed F, Sanganee HJ, Bahl A and Bayat A: Potent dual inhibitors of TORC1 and TORC2 complexes (KU-0063794 and KU-0068650) demonstrate in vitro and ex vivo Anti-Keloid scar activity. J Invest Dermatol 133: 1340-1350, 2013.

12. Wang W, Qu M, Xu L, Wu X, Gao Z, Gu T, Zhang W, Ding X, Liu W and Chen Y: Sorafenib exerts an anti-keloid activity by antagonizing TGF- $\beta /$ Smad and MAPK/ERK signaling pathways J Mol Med (Berl) 94: 1181-1194, 2016.

13. Wong VW, You F, Januszyk M, Gurtner GC and Kuang AA: Transcriptional profiling of rapamycin-treated fibroblasts from hypertrophic and keloid scars. Ann Plast Surg 72: 711-719, 2014.
14. Ong CT, Khoo YT, Mukhopadhyay A, Do DV, Lim IJ, Aalami O and Phan TT: mTOR as a potential therapeutic target for treatment of keloids and excessive scars. Exp Dermatol 16: 394-404, 2007.

15. Fitzgerald O'Connor EJ, Badshah II, Addae LY, Kundasamy P, Thanabalasingam S, Abioye D, Soldin M and Shaw TJ: Histone deacetylase 2 is upregulated in normal and keloid scars. J Invest Dermatol 132: 1293-1296, 2012.

16. Van Beneden K, Mannaerts I, Pauwels M, Van den Branden C and Van Grunsven LA: HDAC inhibitors in experimental liver and kidney fibrosis. Fibrogen Tissue Repair 6: 1, 2013.

17. Miller TA, Witter DJ and Belvedere S: Histone deacetylase inhibitors. J Med Chem 46: 5097-5116, 2003.

18. Qian C, Lai CJ, Bao R, Wang DG, Wang J, Xu GX, Atoyan R, Qu H, Yin L, Samson M, et al: Cancer network disruption by a single molecule inhibitor targeting both histone deacetylase activity and phosphatidylinositol 3-kinase signaling. Clin Cancer Res 18: 4104-4113, 2012.

19. Mondello P, Derenzini E, Asgari Z, Philip J, Brea EJ, Seshan V, Hendrickson RC, de Stanchina E, Scheinberg DA and Younes A: Dual inhibition of histone deacetylases and phosphoinositide 3-kinase enhances therapeutic activity against B cell lymphoma. Oncotarget 8: 14017-14028, 2017.

20. Younes A, Berdeja JG, Patel MR, Flinn I, Gerecitano JF, Neelapu SS, Kelly KR, Copeland AR, Akins A, Clancy MS, et al: Safety, tolerability, and preliminary activity of CUDC-907, a first-in-class, oral, dual inhibitor of HDAC and PI3K, in patients with relapsed or refractory lymphoma or multiple myeloma: An open-label, dose-escalation, phase 1 trial. Lancet Oncol 17: 622-631, 2016.

21. Seifert O and Mrowietz U: Keloid scarring: Bench and bedside. Arch Dermatol Res 301: 259-272, 2009.

22. Wang W, Li J, Wang K, Zhang Z, Zhang W, Zhou G, Cao Y, Ye M, Zou H and Liu W: Induction of predominant tenogenic phenotype in human dermal fibroblasts via synergistic effect of TGF- $\beta$ and elongated cell shape. Am J Physiol Cell Physiol 310: C357-C372, 2016.

23. Arnaoutova I and Kleinman HK: In vitro angiogenesis: Endothelial cell tube formation on gelled basement membrane extract. Nat Protoc 5: 628-635, 2010.

24. Ward Kischer C, Sheridan D and Pindur J: Use of nude (athymic) mice for the study of hypertrophic scars and keloids: Vascular continuity between mouse and implants. Anat Rec 225: 189-196, 1989.

25. Ni C, Li C, Dong Y, Guo X, Zhang Y and Xie Z: Anesthetic isoflurane induces DNA damage through oxidative stress and p53 pathway. Mol Neurobiol 54: 3591-3605, 2017.

26. Koutsogiannaki S, Zha $\mathrm{H}$ and Yuki K: Volatile anesthetic isoflurane attenuates liver injury in experimental polymicrobial sepsis model. Transl Perioper Pain Med 5: 63-74, 2018.

27. Borowiak R, Reichardt W, Kurzhunov D, Schuch C, Leupold J, Krafft AJ, Reisert M, Lange T, Fischer E and Bock M: Initial investigation of glucose metabolism in mouse brain using enriched ${ }^{17} \mathrm{O}$-glucose and dynamic ${ }^{17} \mathrm{O}-\mathrm{MRS}$. NMR Biomed 30 , 2017. doi: 10.1002/nbm.3724.

28. Johansson N, Ahonen $M$ and Kähäri VM: Matrix metalloproteinases in tumor invasion. Cell Mol Life Sci 57: 5-15, 2000.

29. Mogili NS, Krishnaswamy VR, Jayaraman M, Rajaram R Venkatraman A and Korrapati PS: Altered angiogenic balance in keloids: A key to therapeutic intervention. Transl Res 159: 182-189, 2012.

30. Pisacane AM, Picciotto F and Risio M: CD31 and CD34 expression as immunohistochemical markers of endothelial transdifferentiation in human cutaneous melanoma. Cell Oncol 29: 59-66, 2007.

31. Unahabhokha T, Sucontphunt A, Nimmannit U, Chanvorachote P, Yongsanguanchai $\mathrm{N}$ and Pongrakhananon V: Molecular signalings in keloid disease and current therapeutic approaches from natural based compounds. Pharm Biol 53: 457-463, 2015.

32. Bijlard E, Steltenpool S and Niessen FB: Intralesional 5-Fluorouracil in keloid treatment: A systematic review. Acta Derm. Venerol 95: 778-782, 2015.

33. Ud-Din S and Bayat A: New insights on keloids, hypertrophic scars, and striae. Dermatol Clin 32: 193-209, 2014.

34. Mari W, Alsabri SG, Tabal N, Younes S, Sherif A and Simman R: Novel insights on understanding of keloid scar: Article review. J Am Coll Clin Wound Spec 7: 1-7, 2016.

35. Andrews JP, Marttala J, Macarak E, Rosenbloom J and Uitto J: Keloids: The paradigm of skin fibrosis-pathomechanisms and treatment. Matrix Biol 51: 37-46, 2016. 
36. Runyan CE, Schnaper HW and Poncelet AC: The phosphatidylinositol 3-kinase/Akt pathway enhances Smad3-stimulated mesangial cell collagen I expression in response to transforming growth factor-beta1. J Biol Chem 279: 2632-2639, 2004.

37. Lopiccolo J, Blumenthal GM, Bernstein WB and Dennis PA: Targeting the PI3K/Akt/mTOR pathway: Effective combinations and clinical considerations. Drug Resist Update 11: 32-50, 2008.

38. Carracedo A, Ma L, Teruya-Feldstein J, Rojo F, Salmena L, Alimonti A, Egia A, Sasaki AT, Thomas G, Kozma SC, et al: Inhibition of mTORC1 leads to MAPK pathway activation through a PI3K-dependent feedback loop in human cancer. J Clin Invest 118: 3065-3074, 2008.

39. Wee S, Jagani Z, Xiang KX, Loo A, Dorsch M, Yao YM, Sellers WR, Lengauer C and Stegmeier F: PI3K pathway activation mediates resistance to MEK inhibitors in KRAS mutant cancers. Cancer Res 69: 4286-4293, 2009.

40. Jia J, Zhu F, Ma X, Cao ZW, Li YX and Chen YZ: Mechanisms of drug combinations: Interaction and network perspectives. Nat Rev Drug Discov 8: 111-128, 2009.

41. Pei Y, Liu KW, Wang J, Garancher A, Tao R, Esparza LA Maier DL, Udaka YT, Murad N, Morrissy S, et al: HDAC and PI3K antagonists cooperate to inhibit growth of MYC-driven medulloblastoma. Cancer Cell 29: 311-323, 2016.

42. Wozniak MB, Villuendas R, Bischoff JR, Aparicio CB, Martínez Leal JF, de La Cueva P, Rodriguez ME, Herreros B, Martin-Perez D, Longo MI, et al: Vorinostat interferes with the signaling transduction pathway of T-cell receptor and synergizes with phosphoinositide-3 kinase inhibitors in cutaneous T-cell lymphoma. Haematologica 95: 613-621, 2010.

43. Delcuve GP, Khan DH and Davie JR: Targeting class I histone deacetylases in cancer therapy. Expert Opin Ther Tar 17: 29-41, 2013.

44. Kawada J, Ito Y, Iwata S, Suzuki M, Kawano Y, Kanazawa T, Siddiquey MN and Kimura H: mTOR inhibitors induce cell-cycle arrest and inhibit tumor growth in Epstein-Barr virus-associated $\mathrm{T}$ and natural killer cell lymphoma cells. Clin Cancer Res 20: 5412-5422, 2014.

45. Cuyas E, Corominas-Faja B, Joven J and Menendez JA: Cell cycle regulation by the nutrient-sensing mammalian target of rapamycin (mTOR) pathway. Methods Mol Biol 1170: 113-144, 2014.

46. Loos C, Syrovets T, Musyanovych A, Mailänder V, Landfester K and Simmet T: Amino-functionalized nanoparticles as inhibitors of mTOR and inducers of cell cycle arrest in leukemia cells. Biomaterials 35: 1944-1953, 2014.

47. Du L, Risinger AL, King JB, Powell DR and Cichewicz RH: A potent HDAC inhibitor, 1-Alaninechlamydocin, from a Tolypocladium sp. induces G2/M cell cycle arrest and apoptosis in MIA PaCa-2 cells. J Nat Prod 77: 1753-1757, 2014.

48. Feng W, Cai D, Zhang B, Lou G and Zou X: Combination of HDAC inhibitor TSA and silibinin induces cell cycle arrest and apoptosis by targeting survivin and cyclinB1/cdk1 in pancreatic cancer cells. Biomed Pharmacother 74: 257-264, 2015.

49. Ramakrishnan S, Ku S, Ciamporcero E, Miles KM, Attwood K, Chintala S, Shen L, Ellis L, Sotomayor P, Swetzig W, et al: HDAC 1 and 6 modulate cell invasion and migration in clear cell renal cell carcinoma. BMC Cancer 16: 617, 2016.
50. Tian H, Zhang Y, Zhang Q, Li S, Liu Y and Han X: Effects of BENC-511, a novel PI3K inhibitor, on the proliferation and apoptosis of A549 human lung adenocarcinoma cells. Biosci Trends 13: 40-48, 2019.

51. Eto S, Saeki K, Yoshitake R, Yoshimoto S, Shinada M, Ikeda N, Kamoto S, Tanaka Y, Kato D, Maeda S, et al: Anti-tumor effects of the histone deacetylase inhibitor vorinostat on canine urothelial carcinoma cells. PLoS One 14: e0218382, 2019.

52. Huang WW, Tsai SC, Peng SF, Lin MW, Chiang JH, Chiu YJ, Fushiya S, Tseng MT and Yang JS: Kaempferol induces autophagy through AMPK and AKT signaling molecules and causes G2/M arrest via downregulation of CDK1/cyclin B in SK-HEP-1 human hepatic cancer cells. Int J Oncol 42: 2069-2077, 2013.

53. Makarević J, Rutz J, Juengel E, Maxeiner S, Tsaur I, Chun FK, Bereiter-Hahn $J$ and Blaheta RA: Influence of the HDAC inhibitor valproic acid on the growth and proliferation of temsirolimus-resistant prostate cancer cells in vitro. Cancers (Basel) 11: E566, 2019.

54. Sun Z, Cao B and Wu J: Protease-activated receptor 2 enhances renal cell carcinoma cell invasion and migration via PI3K/AKT signaling pathway. Exp Mol Pathol 98: 382-389, 2015.

55. Zhou H, Jiang S, Chen J, Ren X, Jin J and Su SB: Largazole, an inhibitor of class I histone deacetylases, attenuates inflammatory corneal neovascularization. Eur J Pharmacol 740: 619-626, 2014.

56. Bian X, Liang Z, Feng A, Salgado E and Shim H: HDAC inhibitor suppresses proliferation and invasion of breast cancer cells through regulation of miR-200c targeting CRKL. Biochem Pharmacol 147: 30-37, 2018.

57. Luo K: Signaling cross talk between TGF- $\beta /$ Smad and other signaling pathways. Cold Spring Harb Perspect Biol 9: a022137, 2017.

58. Guo W, Shan B, Klingsberg RC, Qin X and Lasky JA: Abrogation of TGF-beta1-induced fibroblast-myofibroblast differentiation by histone deacetylase inhibition. Am J Physiol Lung Cell Mol Physiol 297: L864-L870, 2009.

59. Bettinger DA, Yager DR, Diegelmann RF and Cohen KI: The effect of TGF-beta on keloid fibroblast proliferation and collagen synthesis. Plast Reconstr Surg 98: 827-833, 1996.

60. Peltonen J, Hsiao LL, Jaakkola S, Sollberg S, Aumailley M, Timpl R, Chu $\mathrm{M}$ and Uitto $\mathrm{J}$ : Activation of collagen gene expression in keloids: Co-localization of type I and VI collagen and transforming growth factor-beta1 mRNA. J Invest Dermatol 97: 240-248, 1991.

61. Lim IJ, Phan TT, Tan EK, Nguyen TT, Tran E, Longaker MT, Song C, Lee ST and Huynh HT: Synchronous activation of ERK and phosphatidylinositol 3-kinase pathways is required for collagen and extracellular matrix production in keloids. J Biol Chem 278: 40851-40858, 2003.

This work is licensed under a Creative Commons Attribution-NonCommercial-NoDerivatives 4.0 International (CC BY-NC-ND 4.0) License. 